\title{
Unawareness of Olfactory Dysfunction in Older Adults
}

\author{
Amal Loudghi ${ }^{1,2}$, Majed Alotaibi ${ }^{1,2}$, Melissa Lessard-Beaudoin ${ }^{1,2}$, Denis Gris ${ }^{3}$, Kate Busch $^{1}$, Pierrette \\ Gaudreau $^{4,5}$ and Rona K Graham ${ }^{1,2^{*}}$
}

${ }^{1}$ Research Centre on Aging CIUSSS de l'Estrie - CHUS, University of Sherbrooke, Sherbrooke, Canada
${ }^{2}$ Department of Pharmacology and Physiology, University of Sherbrooke, Sherbrooke, Canada

${ }^{3}$ Department of Pediatrics, University of Sherbrooke, Sherbrooke, Faculty of Medicine and Health Sciences, Sherbrooke, Quebec, Canada

${ }^{4}$ Department of Medicine, University of Montreal, Quebec, Canada

${ }^{5}$ Centre Hospitalier de l'Université de Montréal Research Center, Montreal, Quebec, Canada

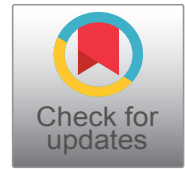

*Corresponding author: Rona K Graham, PhD, Department of Pharmacology and Physiology, University of Sherbrooke, Sherbrooke, Canada

\begin{abstract}
Deterioration of olfaction is a common phenomenon observed in the senior population. A number of factors may cause this deficit including infections, aging and neurodegenerative diseases. The aim of this study was to evaluate the reliability of the self-report as a measure of olfactory function in seniors. A total of 93 community-dwelling participants (43 men and 50 women) from the Quebec NuAge cohort on Nutrition and Successful Aging participated in the Olfactory Response and Cognition in Aging (ORCA) study. The age range was $80-95$ years and all subjects had a telephone mini mental state examination (t-MMSE) score $>18$. Individuals were interviewed using a self-report ("do you suffer from smell problems?") and quantitative (University of Pennsylvania Smelling Identification Test (UPSIT)) olfactory tests. Based on the self-report, $81 \%$ of the participants claimed to have a normal sense of olfaction. However, based on the UPSIT, $95 \%$ of them showed different forms of microsmia. These results reveal that most senior citizens are unaware of their olfactory dysfunction and indicate that an self-report questionnaire is not a valid instrument to assess olfactory function in the aging population.
\end{abstract}

\section{Keywords}

Aging, elderly, Metacognition, Olfaction, Self-evaluation

\section{Abbreviations}

NuAge: Quebec NuAge Cohort on Nutrition and Successful Aging; ORCA: Olfactory Response and Cognition in Aging Study; t-MMSE: Telephone Mini Mental State Examination; UPSIT: University of Pennsylvania Smelling Identification Test; AD: Alzheimer Disease; HD: Huntington Disease; $\mathrm{MCl}$ : Mild Cognitive Impairement

\section{Introduction}

From a phylogenetic perspective, olfaction is deemed one of the oldest sensory systems in mammals [1]. Often taken for granted, the sense of smell is of crucial importance. Although olfaction may appear to have less importance in identifying objects or people compared to vision, this sense plays a crucial social and emotional role which affects an individual's tastes and food preferences daily [2]. Furthermore, olfaction represents a strong asset when it comes to detecting danger through odours such as gas leaks and/or other toxic fumes, smoke and rotting food. Strong evidence indicates that olfactory dysfunction occurs with aging [3]. From this perspective, olfactory dysfunction is a major public health concern and measures need to be put in place to alleviate these dangers.

Several factors have been identified that may cause olfactory dysfunction including stroke, viral infections and aging [4-6]. Age-related olfactory dysfunction is characterized by a significant decrease in adrenergic innervation density in the lamina propria of the olfactory mucosa [7]. Other factors implicated in the loss of olfactory function include air-flow and mucous composition, structure of the olfactory neuroepithelium and bulb, and olfactory processing in the brain [8]. The deterioration of smell due to age is often gradual and therefore not noticeable by the affected individual. Many older subjects with microsmia are completely unaware of

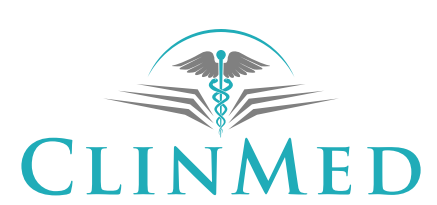

INTERNATIONAL LIBRARY
Citation: Loudghi A, Alotaibi M, Lessard-Beaudoin M, Gris D, Busch K, et al. (2019) Unawareness of Olfactory Dysfunction in Older Adults. Int J Neurol Neurother 6:086. doi.org/10.23937/2378-3001/1410086 Accepted: July 13, 2019: Published: July 15, 2019

Copyright: (C) 2019 Loudghi A, et al. This is an open-access article distributed under the terms of the Creative Commons Attribution License, which permits unrestricted use, distribution, and reproduction in any medium, provided the original author and source are credited. 


\section{A NuAge}

T1 $\mathbf{T 2} \quad \mathbf{T 3} \quad \mathbf{T 4}$

$200420052006 \quad 2008$

ORCA

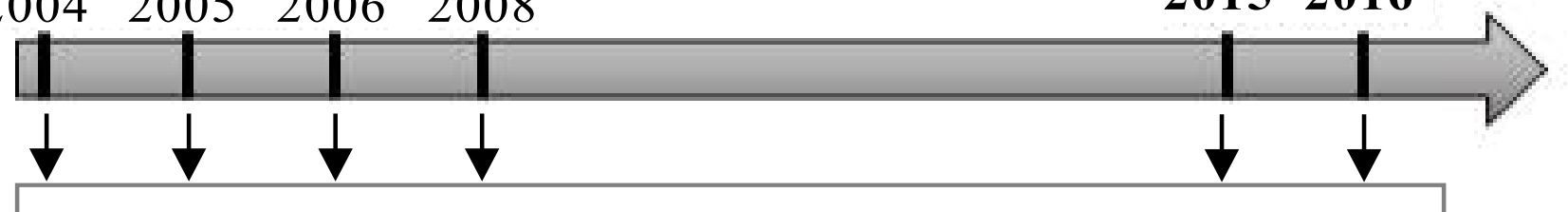

Self-report : Do you have problems with the sense of smell? Such as decreased smell perception or smelling non-appropriate odors. Response options: "No", "Yes", "I don't know" and "If yes, which one? Complete loss of the sense of smell, partial loss of the sense of smell, non-appropirate odors, or I don't know".
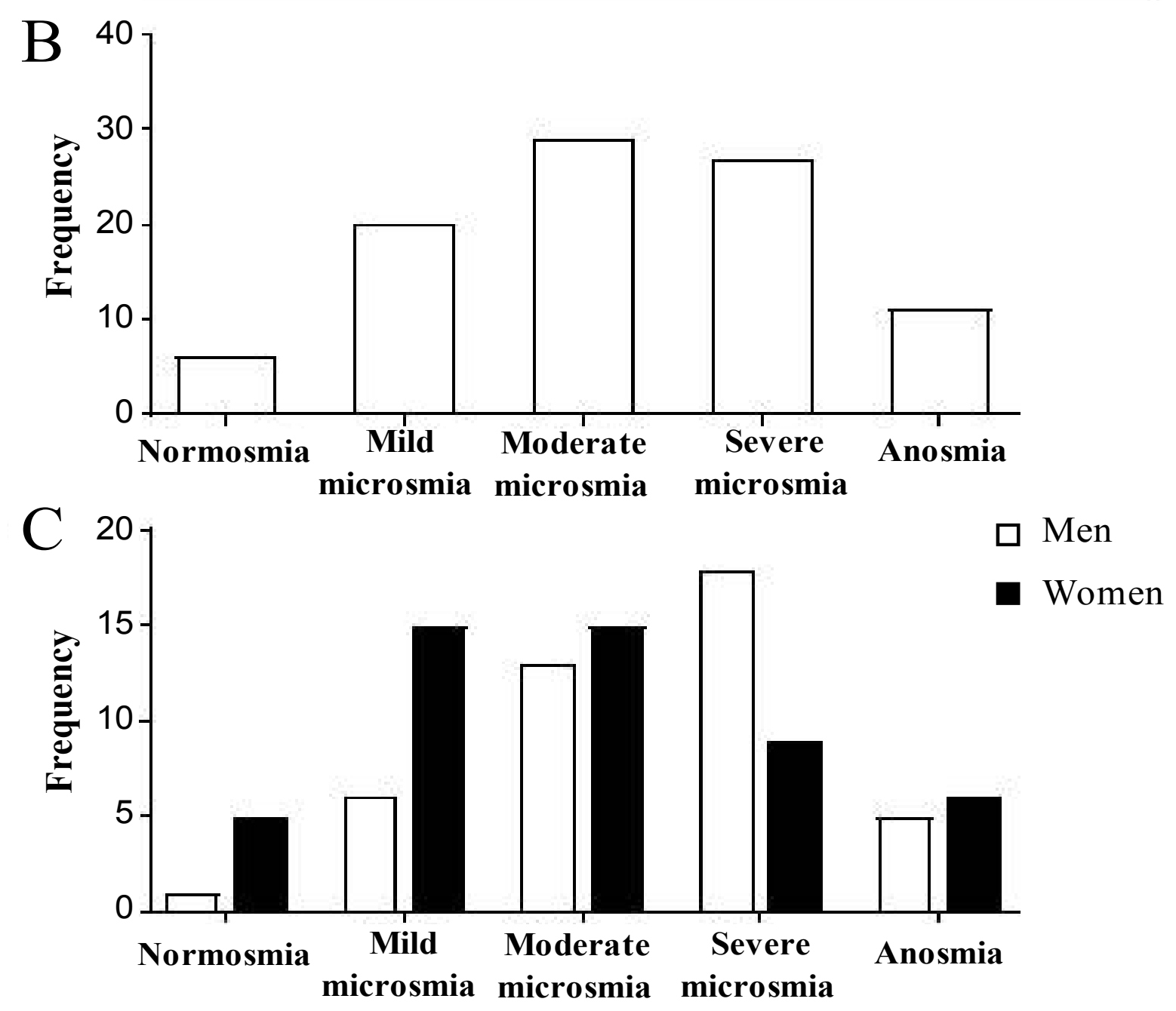

Figure 1: Experimental design of the ORCA study. The self-report was completed at all the time-points (NuAge study: T1- T4, ORCA: 2015 and 2016). A) The last self-report (2016), was done at the same time as the UPSIT test in front of the evaluator. The t-MMSE was done in 2015. Olfactory dysfunction is common among seniors citizen. B) $94 \%$ (87/93) of participants have one of the forms of microsmia (males and females combined). C) No difference in the distribution of olfactory status is observed between sex (Chi-squared, $p=0.074)$.

their olfactory state [9-11]. Unawareness of olfactory impairment may be caused by the lack of attention towards a stimulus. It has been shown that attention is necessary for olfactory consciousness [12] and that the auto-evaluation of the olfactory functions correlates with the quantitative olfactory test scores only after assessing the olfactory function [13]. In addition, many people suffering from olfactory dysfunction tend to mistake their impairment for a taste loss rather than a smell loss [14]. 
A study performed in Sweden and Norway, which included healthy participants between the age of 4579 , has demonstrated that unawareness of anosmia (complete loss of olfaction) is frequent in older adults (79\%) who have healthy cognitive abilities based on a comprehensive neurological assessment [15]. In a similar study, conducted in the United States on adults aged 53 to 79 years, only $20 \%$ of subjects who suffered from anosmia were aware of having problems with olfaction [16]. The general consensus in the literature, based on the limited studies conducted thus far, supports the hypothesis that seniors are unaware of their olfactory impairment $[10,13,17]$. However, there are some studies which demonstrate that elderly subjects were able to estimate their olfactory function $[18,19]$.

Substantial evidence in the literature has shown that olfactory dysfunction is observed in several neurodegenerative diseases, such as Alzheimer disease (AD), Huntington disease (HD) and Stroke and Parkinson disease (PD) among others [20]. Importantly, several studies suggest that olfactory dysfunction may represent an early predictor of future cognitive impairment [21-23]. Indeed, olfactory impairment is currently seen as one of the top predictors of impending PD and is observed in Mild Cognitive Impairment ( $\mathrm{MCl})$, a potential precursor of AD [24,25]. This highlights the importance of establishing robust tests that reveal a smell disorder in an older individual.

Importantly, unawareness of olfactory problems may lead to malnutrition and depression $[26,27]$. In addition, affected individuals will not be able to access their olfactory memories which may contribute to the depression [28]. This becomes a prominent concern considering that depression in individuals with $\mathrm{MCl}$ more than doubles the risk for progression to $A D$ [29]. In this report, we wished to determine if the olfactory self-report is a reliable method to determine olfactory function as there is limited information in the literature. We assessed an aging population in the province of Quebec and compared the performance of the self-evaluation method to the quantitative evaluation of olfaction in this same population.

\section{Materials and Methods}

\section{Participants}

A total of 93 individuals (50 females (age range 80-
95), 43 males (age range 80-93)) from Quebec, agreed to participate in the clinical sub-study Olfactory Response and Cognition in Aging (ORCA) (Figure 1, given separately). The participants were recruited from the large database of the Quebec Longitudinal Study on Nutrition and Successful Aging (NuAge) in which only healthy and cognitively fit adults ( $>67$ years of age) were included [30]. The NuAge study recruited 1,793 individuals who were assessed annually between 2004-2008. For the ORCA study, initial calls were made to the previous NuAge participants asking if they would consider to be involved in other studies and/or the ORCA sub-study. For those who agreed to be involved, the telephone Mini Mental State Examination (t-MMSE) was done and only cognitively fit adults ( $\geq 18$ ) were admitted into the ORCA sub-study. Letters were then sent out which included a self-report olfaction questionnaire (identical to original NuAge self-report) (2015) and a consent form. All the subjects signed the consent form in their native language which was approved by the Research Centre of Aging ethical committee (Quebec REB 2015-477). At the time of the NuAge study, no participants reported diagnosed neurological diseases, such as Parkinson disease, Huntington disease and/or Stroke. The characteristics of the participants are presented in Table 1 (Given separately).

\section{Self-Report}

NuAge applicants filled in self-report forms about their olfactory state each year from 2004-2008 (T1-T4) which included the questions: "Do you have problems with the sense of smell? Such as decreased smell perception or smelling non-appropriate odor. Response options: "No", "Yes", "I don't know" and "If yes, which one? Complete loss of the sense of smell, partial loss of the sense of smell, non-appropriate odors, or I don't know". In 2015/2016, 93 of these participants, who now make-up the ORCA sample also completed a self-report questionnaire (identical to original NuAge self-report) at the time of the signature of the consent form. Another self-report was completed in front of an evaluator in 2016, at the same time of the assessment of the University of Pennsylvania smell Identification Test (UPSIT) test.

\section{Olfactory Evaluation}

The UPSIT, the gold-standard for quantitative as-

Table 1: Descriptive characteristic of study participants.

\begin{tabular}{|l|l|l|l|}
\hline & Women & Men & p value \\
\hline Age & $85.8 \pm 3.8$ & $85.4 \pm 3.9$ & 0.58 \\
\hline UPSIT & $27.6 \pm 6.8$ & $25.3 \pm 5.1$ & 0.07 \\
\hline Education (years) & $12.5 \pm 4.0$ & $15.7 \pm 4.2$ & $0.0004^{* * *}$ \\
\hline Smoking & & & $0.009^{* *}$ \\
\hline Never & 31 & 15 & \\
\hline Past & 19 & 28 & \\
\hline Current & 0 & 0 & \\
\hline
\end{tabular}


Table 2: Participants distribution of qualitative (2015 self-report) and quantitative (UPSIT) level of olfaction.

\begin{tabular}{|c|c|c|c|c|}
\hline \multirow[t]{2}{*}{ OLFACTION DIAGNOSIS } & Self-report & Women $(n=50)$ & Men $(\mathrm{N}=43)$ & Total $(\mathrm{N}=93)$ \\
\hline & Answer & Age (80-95) & Age (80-93) & age (80-95) \\
\hline \multirow[t]{3}{*}{ Normosmia (\%) } & No & $6(3 / 50)$ & $2.3(1 / 43)$ & $4.3(4 / 93)$ \\
\hline & Yes & $4(2 / 50)$ & $0(0 / 43)$ & $2.2(2 / 93)$ \\
\hline & I don't know & $0(0 / 50)$ & $0(0 / 43)$ & $0(0 / 93)$ \\
\hline \multirow[t]{3}{*}{ Mildmicrosmia (\%) } & No & $24(12 / 50)$ & $16.2(7 / 43)$ & $20.4(19 / 93)$ \\
\hline & Yes & $2(1 / 50)$ & $0(0 / 43)$ & $1.1(1 / 93)$ \\
\hline & I don't know & $2(2 / 50)$ & $0(0 / 43)$ & $2.2(2 / 93)$ \\
\hline \multirow[t]{3}{*}{ Moderatemicrosmia (\%) } & No & $28(14 / 50)$ & $23.3(10 / 43)$ & $25.8(24 / 93)$ \\
\hline & Yes & $2(1 / 50)$ & $0(0 / 43)$ & $1.1(1 / 93)$ \\
\hline & I don't know & $0(0 / 50)$ & $4.7(2 / 43)$ & $2.2(2 / 93)$ \\
\hline \multirow[t]{3}{*}{ Severemicrosmia (\%) } & No & $12(6 / 50)$ & $37.2(16 / 43)$ & $23.7(22 / 93)$ \\
\hline & Yes & $4(2 / 50)$ & $2.3(1 / 43)$ & $3.2(3 / 93)$ \\
\hline & I don't know & $2(1 / 50)$ & $2.3(1 / 43)$ & $2.2(2 / 93)$ \\
\hline \multirow[t]{3}{*}{ Anosmia (\%) } & No & $6(3 / 50)$ & $7(3 / 43)$ & $6.5(6 / 93)$ \\
\hline & Yes & $6(3 / 50)$ & $2.3(1 / 43)$ & $4.3(4 / 93)$ \\
\hline & I don't know & $0(0 / 50)$ & $2.3(1 / 43)$ & $1.1(1 / 93)$ \\
\hline Total (\%) & & 100 & 100 & 100 \\
\hline
\end{tabular}

sessment of olfaction, is commercially available as the Smell Identification Test (SIT, Sensonics, Inc.) and is the most widely used quantitative olfactory test [20]. It contains four booklets with a total of 40 different odors. Each smell is micro-encapsulated which are released by scratching a lead pencil. The participant must provide the most appropriate answer between four alternatives forced choices. The test is rated on a maximum score of 40 and each score range corresponds to an olfactory diagnosis (described in the UPSIT manual). The staff who conducted the interviews were trained and familiar with the olfactory tests. A \$10 compensation was given to each participant to cover incidentals such as parking.

\section{Statistical Analysis}

The results of the qualitative and quantitative olfactory tests were first compiled by the administrator who performed them and rechecked twice by two other administrators. The qualitative results taken in 2015/2016 were compared with those taken between 2004 and 2008 (T1 - T4), and then compared to the quantitative results. We also compared the results obtained in 2015 and 2016 together. All statistical analysis was performed with Graphpad Prism 7 software. Cochran's Q tests were used to compare frequencies of self-report answers in time, and chi-square tests to compare frequencies of self-report and objective assessment between sex. T-test between independent groups (age, education and raw UPSIT) and Chi square (smoking status) were used to compare the characteristic of men vs. women in Table 1 (Given separately). The equality of variances was analysed using the F-test and the variance between man and women were not significantly different for all the variables assessed. The level of significance was set at $p<0.05$. The measure of the sensitivity (correctly identify those with the disease) and specificity (correctIy identify those without the disease) of the self-report was calculated by comparing the self-report results with the olfactory status evaluated by the UPSIT score.

\section{Results}

The results of the 2015/2016 quantitative olfactory tests are shown in Table 2 (Given separately). According to the quantitative results harvested in 2015/2016, $94 \%(87 / 93)$ of participants suffered from one of the forms of hyposmia (mild $(24 \%)$, moderate $(29 \%)$ or severe microsmia (29\%) and total anosmia (12\%)) (Table 2 , Figure 1A, Figure 1B given separately). Even if we took into the account only the most severe forms of olfactory dysfunction (moderate, severe microsmia and anosmia) that are the most likely to affect the safety and quality of life, the percentage was still quite high $(70 \%, 65 / 93)$. We then compared the results across sex. The distribution of olfactory status was not significantly different between the men and women in our population (Figure $1 C$, Chi-squared $p=0.074$, given separately). However, the percentage of individuals who suffer from mild microsmia was $18 \%$ higher in women, while the percentage of severe microsmia was $24 \%$ higher in men.

We next compared the quantitative UPSIT olfactory score with the responses on the self-report questionnaire. In sharp contrast to the quantitative results, the qualitative self-report of 2015/2016 demonstrates that $81 \%(75 / 93)$ of participants claimed not to suffer from any problems with olfaction (Figure $2 \mathrm{~A}$, given separately). Within these 75 individuals, 95\% (71/75) had some form of microsmia. It is worth mentioning that $91 \%$ $(10 / 11)$ of subjects who claimed to have olfactory dys- 
A

Both gender

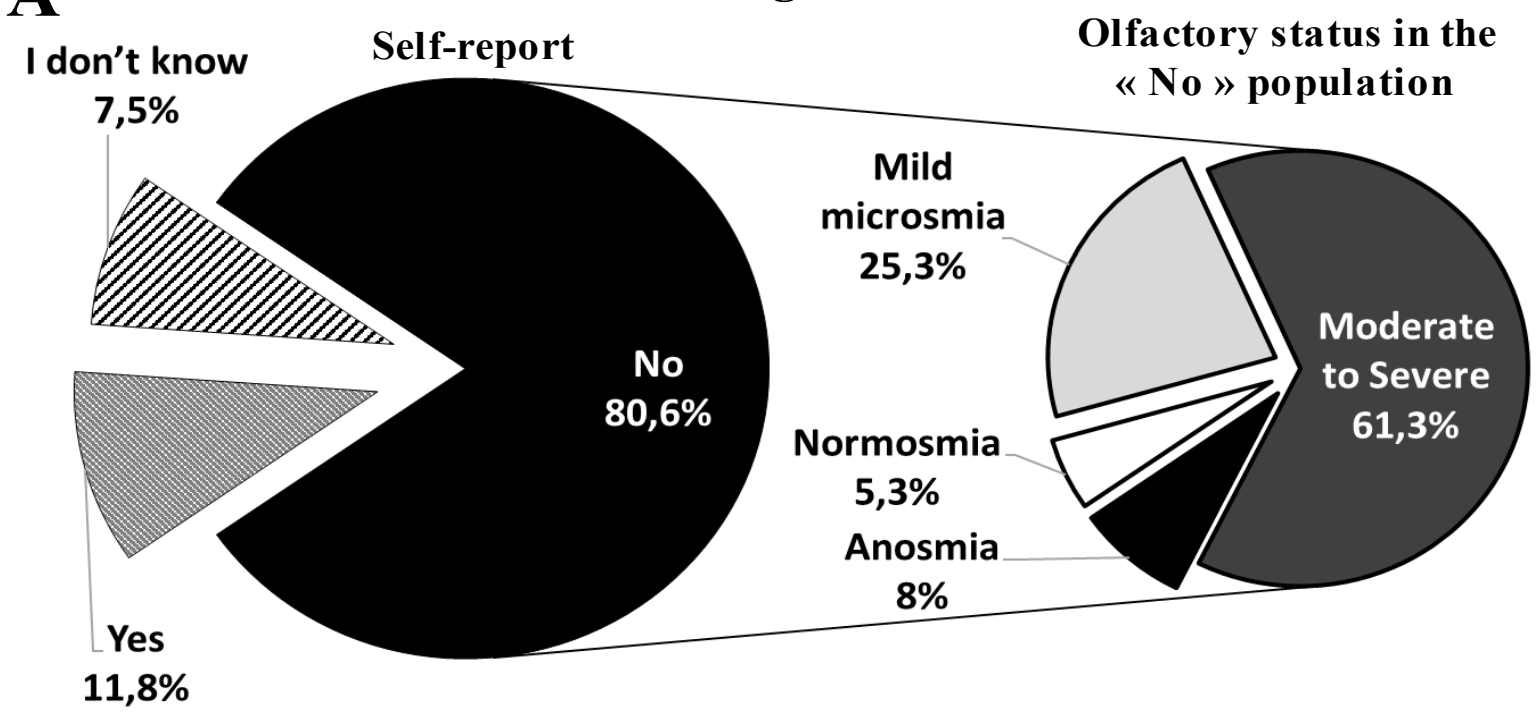

\section{B}

I don't know

$6 \%$ Self-report

Women

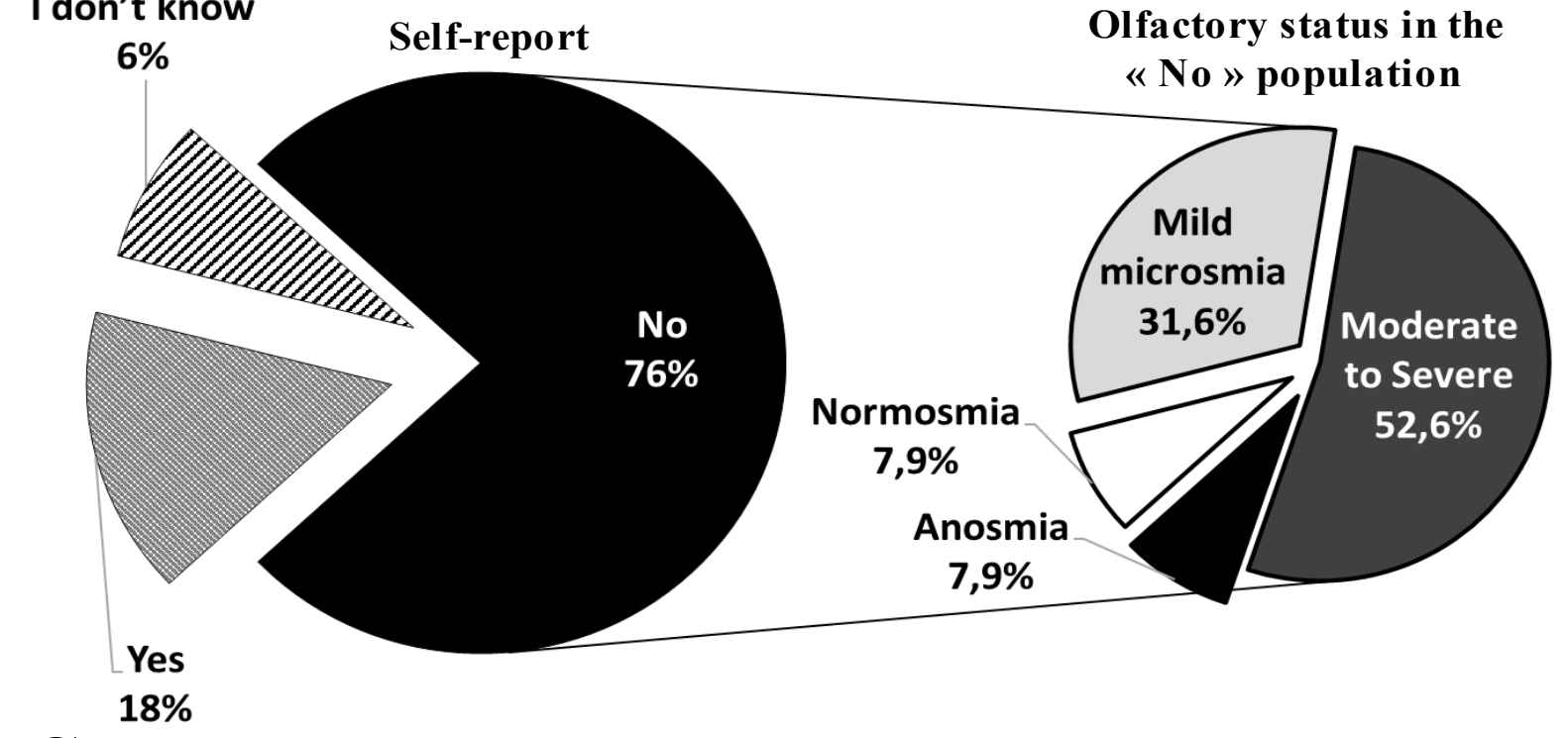

C

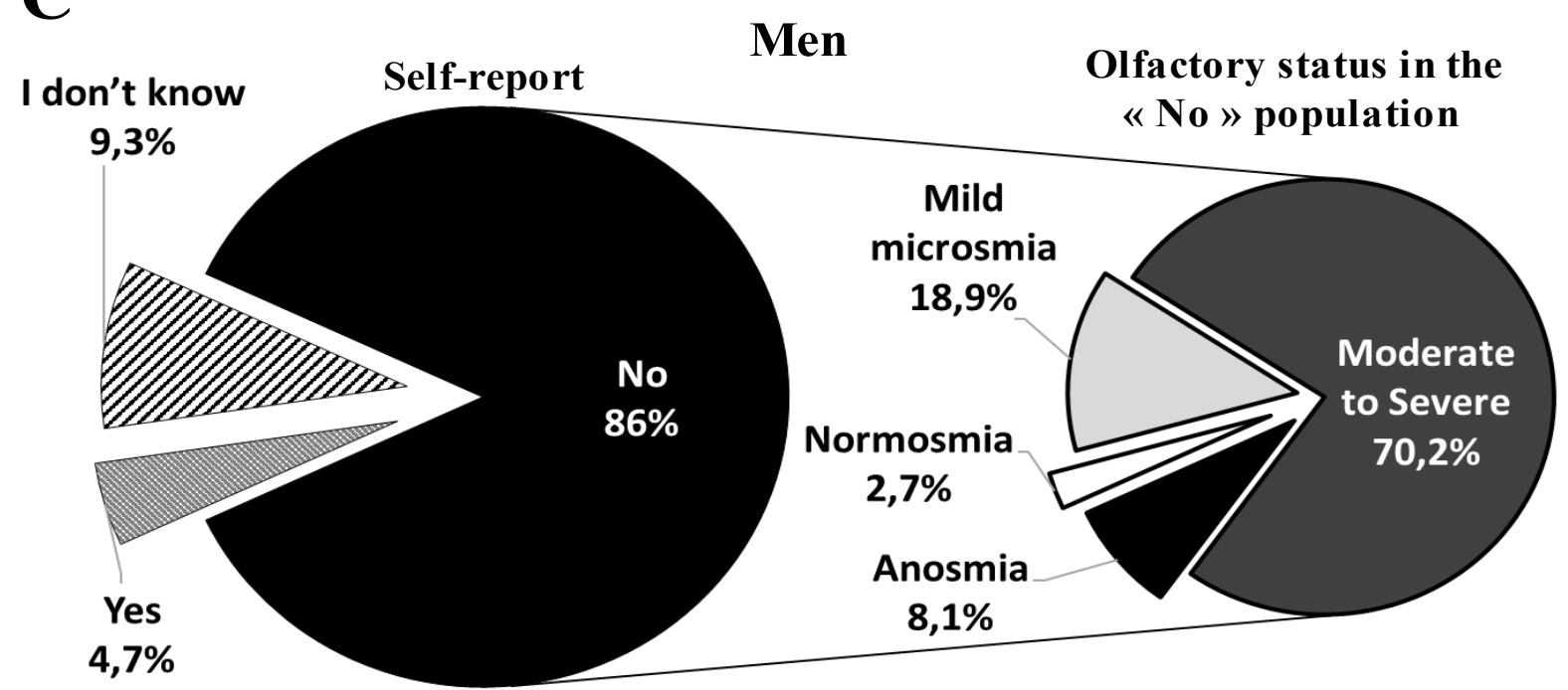

Figure 2: Unawareness of olfactory dysfunction is not sex-related. A) Distribution of the self-report assessment and UPSIT result in the participants (males and females combined) who answered "No". B) Distribution of the self-report assessment and UPSIT result in women who answered "No". C) Distribution of the self-report assessment and UPSIT result in men who answered "No". No significant difference is detected in the olfactory status between men and women for the subjects who answered "No" (Chi-squared, $p=0.11)$. 
function did suffer from it according to UPSIT score. In addition, 7 out of 93 participants reported not knowing their olfactory state and 6 of those individuals had microsmia.

We next looked at the distribution of the different olfaction states in those who claimed not to suffer from olfactory dysfunction by sex (Figure 2B, Figure 2C, given separately). For females, $76 \%$ responded that they had no olfactory impairment, however, 92\% (35/38) had deficits as detected by the UPSIT $(8 \%(3 / 38)$ normosmia, 32\% (12/38) microsmia, 37\% (14/38) moderate microsmia, $16 \%(6 / 38)$ severe microsmia and $8 \%(3 / 38)$ total anosmia) (Figure 2B, Table 2, Given separately). We found a similar situation in the male population, with $86 \%$ declaring no deficits when in fact $97 \%(36 / 37)$ did demonstrate problems with smell according to UPSIT (3\% (1/37) normosmia, 19\% (7/37) mild microsmia, $27 \%$ (10/37) moderate microsmia, 43\% (16/37) severe microsmia and $8 \%(3 / 37)$ total anosmia) (Figure 2C, Table 2, given separately). Of note, in the group who claimed not to suffer from any problems with smells, the difference in the frequency of microsomia between men and women was not significant $(p=0.11)$. These results demonstrate that while the majority of individuals in our sample claim not to have any problems with smell, they actually had different forms of microsmia. The overall sensitivity of the self-report was $12.3 \%$ and the specificity was $80 \%$.

The evaluation of the individual's assessment of their olfactory function (self-report) was then evaluated over the years 2004 to 2008 (T1-T4), and in 2015/2016 (Figure 3 , given separately). Fluctuations in the percentages of individuals who reported "no" to the question "do you suffer from any problems in smell" did not change significantly over the years (Cochran's $Q$ test, $p=0.11$ ). The number of individuals reporting no olfactory dys- function represents the majority of the subjects ( $81 \%$ in 2015). We also compared the results of the self-report done in 2015 and 2016 to see if the presence of an evaluator affected the answer of the participant. Despite the fact that there was no significant variation between the answers in 2015 and 2016 ( $p=0.74$, data not shown), we observed some individual variations. Indeed, 5 of the 11 individuals who reported a problem with smell in 2015 changed the answer to "No" in front of the evaluator. Interestingly, one of these participants reported a complete loss of smell in 2015. Of note, only 4 of the individuals who reported no problem with sense of smell in 2015 changed their answer to yes at 2016 in front of the evaluator.

We then focused on the consistency of the self-report responses by analyzing the proportion of individuals who maintained the same response on their olfactory self-report over time. It may be expected that the elderly participants would change their answer from "no" to "yes" to the question "do you suffer from any problems in smell" as their olfaction deteriorates over the years. However, the opposite effect was noticed. Indeed, $88 \%$ of the participant who responded "no" at T1 maintained their answer throughout the 5 timepoints (64/73 participants). In sharp contrast, only 1 out of 8 participants who responded "yes" maintained his answer throughout the years. Despite the fact that almost all the participants who responded "yes" changed their answer over the years, the variation over time was not significant. This may be explained by the small proportion of individuals who claimed to have an olfactory problem in the self-report (Cochran's $Q$ test, "no" $p=$ $0.001 ;$ “yes" $p=0.1$.

\section{Discussion}

From the quantitative olfactory test (UPSIT), our re-

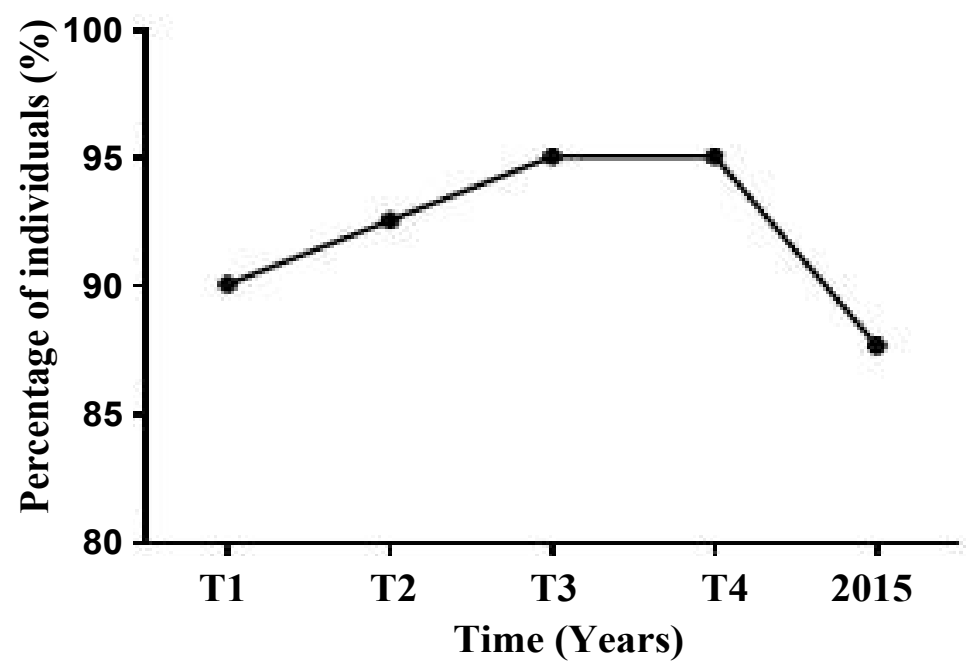

Figure 3: Percentage of self-reporting rates on the state of olfaction of participants did not change between 2004 and 2016. The percentage of individuals who reported no olfactory deficits remained stable over time (Cochran's $Q$ test, $p=0.11$ ). For the purpose of the statistical analysis, the answer 'I don't know' were discarded from the analysis. 
sults demonstrate that $94 \%(87 / 93)$ of the participants have olfactory problems. In contrast, the result of the self-report (2015) demonstrates that $81 \%$ of participants claimed not to suffer from any problems with olfaction. Furthermore, the majority of the participants who appeared to be aware of their olfactory dysfunction in 2004 then subsequently changed their answer about their olfaction as they became unaware of it. Additionally, our results show that unawareness of olfactory dysfunction is not sex-related. The fact that humans undergo a gradual decline in olfaction with age [20] may make them less aware of their loss over time $[11,31]$. Indeed, the objective of this study was to determine whether unawareness of olfactory impairment is a common problem in cognitively well-functioning seniors. Furthermore, the goal was to evaluate the reliability of the olfactory self-reports as a way to determine olfactory capabilities among the elderly in the clinic. These objectives were carried out by comparing the qualitative test of olfaction with the quantitative test (UPSIT) on participants aged 80 to 95 years. Despite the relatively high specificity (correct identification of normosmia) of the self-report (80\%), the sensitivity (correct identification of olfactory dysfunction) was very poor (12\%) suggesting that the self-report is not a reliable test to diagnose olfactory impairment among the senior population.

Similar to other studies, our results demonstrate that the majority of elderly individuals have olfactory deficits [16]. However, what is more alarming is that $69 \%$ ( $95 \%$ if we include mild microsomia) of the participants who claimed to have no olfactory dysfunction were not aware of their actual olfactory dysfunction. The lack of association between the self-report and measured olfaction may also be a result of the fact that the majority of studies on olfaction in the elderly used a self-report that include only a single question $[10,11,15]$. There are only four studies on olfactory awareness that use the multiple questions self-report $[10,15,18,32]$. One of these studies, done on only women, shows an association between the self-report and olfactory function [18], another study demonstrated an association only in the population with Alzheimer's disease and the others show no correlation [32].

Interestingly, it has been shown that older individuals are not more likely in general to make errors in the estimation of their faculties compared to the younger individuals. However, they tend to overestimate their olfactive faculties, while the younger population are more likely to underestimate them (White \& Kurtz, 2003). This represents a significant practical danger for seniors as more than $32 \%$ women and $16 \%$ men over 65 years old was living alone in 2011 according to statistics Canada [33] and who may be exposed to several risks of everyday life such as detecting gas leaks, toxic substances, smoke or outdated food.
It should be noted that from 2004 to 2016 , only $10 \%$ of the participants switched their answer in the self-report from no to yes. In the opposite case, $45 \%$ of participants changed their statement from yes to no, a rather significant change. We also compared the proportion of the subjects who maintained the same answer through the years. $86 \%$ of the subjects who declared 'no' maintained their answer ( $10 \%$ changed their answer for 'yes' and $5 \%$ for 'I don't know'). However, only $27 \%$ of the individuals maintained 'yes' as an answer throughout the years ( $45 \%$ changed their answer to 'No' and $27 \%$ for 'I don't know'). This may be explained by the fact that unawareness of olfactory dysfunction is common in older people and is not improving with increasing age. The fact that $72 \%$ of the participants have disowned their olfactory problems may be due to a deterioration of their olfactory memory since the majority of this specific subgroup of participants (7/11) seemed to suffer from anosmia or a severe form of microsmia. In other words, even though these participants had previously acknowledged their olfactory impairment, they then seemed to forget that they had microsmia. These results suggest that self-reports are a very subjective measure of olfaction and are not sensitive nor specific enough to reflect the true olfactory state of the individual.

Olfactory dysfunction has a high prevalence in neurodegenerative diseases such as $A D, P D$ and $H D$ $[8,34]$ and strong evidence demonstrates that this is an early event in a number of neurological diseases and may be a harbinger of future cognitive impairment $[35,36]$. Based on our results and the results of others, it becomes critical to establish quantitative olfactory testing in the clinic for seniors in order to provide education around non-olfactory avoidance of hazardous events (smoke and gas detectors, dating food, fireescape plans) and to highlight treatment alternatives for olfactory dysfunction [37-40] and mental issues related to olfactory loss (depression, loss of appetite). Importantly, quantitative olfactory testing would enable reliable and robust levels of olfactory functions to be determined in the elderly in order to triage which senior individuals should then go on to have other markers assessed for neurodegenerative diseases. To this day there is no widely adopted policy or clinical algorithm in place for the detection of individuals that have early dementia or indeed may be on the road to cognitive impairment and a neurodegenerative disease. This is despite the fact that there are preventive strategies for dementia-related diseases that have been reliably shown to delay disease progression (healthy eating, exercise and social interactions amongst others) [4145]. Significant savings of lives, and in health-related expenses, could be realized should these measures be put into wide spread clinical use.

Screening pocket olfactory tests need to become routine in the health-care practices. A number of such tests are available including Smell diskettes which can 
be reused. The UPSIT remains to date the most commonly used test for olfaction. However, there are time constraints with this test. There are several shorter olfaction tests that are less expensive, and the data would suggest they may be suitable as a first screen (Supplemental Table 1, Given separately). As an example, The Pocket Smell is a very brief test that contains only three different odors and has been shown to be highly sensitive in detecting olfactory dysfunction [46]. If the individual misidentifies one of the three odors, then the B-SIT and/or the UPSIT (which contains 40 odors) could be used to further investigate the level of microsmia. In order to consider the best interest of seniors, as well as the financial burden of potential impending neurodegenerative diseases, we would suggest doing olfactory screening, using a quantitative olfaction identification test, on individuals $>50$ years as part of their annual medical check-up.

In conclusion, the results of this clinical study suggest that unawareness of olfactory dysfunction is very common in the aging population and that the self-report is not a reliable method for assessing olfactory status of seniors. Until this day, some studies consider the reliability of self-reports against quantitative tests still debatable [18,32]. However, the majority of the findings in the literature supports the opposite $[10,13,17]$. Our study demonstrates that the quantitative tests are more reliable, and more objective, when it comes to evaluating an individual's sense of smell. Our findings conclude that there is discrepancy between the olfactory self-reports and quantitative tests.

\section{Funding}

This work was supported by a grant from the University of Sherbrooke Merck Sharp \& Dohme; the Research Centre of Aging; in part, by the Canada Research Chairs program (RKG) and the Pfizer-Fonds de recherche du Québec -Santé program. The NuAge study was supported by the Canadian Institutes of Health Research (CIHR); the Consortium for the early identification of Alzheimer's disease-Quebec and the Quebec Network for Research on Aging. AL holds a studentship from the University of Sherbrooke. MA received a PhD grant from the King Abdullah International Medical Research Centre.

\section{Acknowledgements}

The authors wish to thank the men and women of the NuAge cohort for their generous and enthusiastic participation in the study, and the retired principal investigators of the NuAge study, Hélène Payette (University of Sherbrooke) and Katherine Gray-Donald (McGill University), for their invaluable scientific contribution. We also wish to thank the NuAge principal investigators, Bryna Shatenstein and José Morais, for their contribution to the study.

\section{Conflict of Interests}

The authors declare that they do not have any conflicts of interest.

\section{Authorship Contribution}

$A L, M L B, M A, K B$ and RKG performed the olfactory test on the participants. $A L, M A$ and MLB analyzed the self-reports and the olfactory tests results. $A L$ and $M L B$ performed to statistical analysis. AL, MA, MLB and RKG wrote the manuscript. $P G$ was involved in the original NuAge study.

\section{References}

1. Brattoli M, de Gennaro $G$, de Pinto V, Loiotile $A D$, Lovascio $S$, et al. (2011) Odour detection methods: olfactometry and chemical sensors. Sensors 11: 5290-5322.

2. Sarafoleanu C, Mella C, Georgescu M, Perederco C (2009) The importance of the olfactory sense in the human behavior and evolution. J Med Life 2: 196-198.

3. Zhang C, Wang $X$ (2017) Initiation of the age-related decline of odor identification in humans: A meta-analysis. Ageing Research Reviews 40: 45-50.

4. Doty RL, Shaman $P$, Applebaum SL, Giberson R, Siksorski L, et al. (1984) Smell identification ability: changes with age. Science 226: 1441-1443.

5. Lee DY, Lee WH, Wee JH, Kim J-W (2014) Prognosis of postviral olfactory loss: follow-up study for longer than one year. Am J Rhinol Allergy 28: 419-422.

6. Wehling E, Naess $\mathrm{H}$, Wollschlaeger D, Hofstad $\mathrm{H}$, Hofstad $\mathrm{H}$, et al. (2015) Olfactory dysfunction in chronic stroke patients. BMC Neurol 15: 199.

7. Chen Y, Getchell TV, Sparks DL, Getchell ML (1993) Patterns of adrenergic and peptidergic innervation in human olfactory mucosa: age-related trends. The Journal of Comparative Neurology 334: 104-116.

8. Alves J, Petrosyan A, Magalhães R (2014) Olfactory dysfunction in dementia. World J Clin Cases 2: 661-667.

9. Schiffman SS (1993) Perception of taste and smell in elderly persons. Crit Rev Food Sci Nutr 33: 17-26.

10. Wehling E, Nordin S, Espeseth T, Reinvang I, Lundervold AJ (2011) Unawareness of olfactory dysfunction and its association with cognitive functioning in middle aged and old adults. Arch Clin Neuropsychol 26: 260-269.

11. White TL, Kurtz DB (2003) The relationship between metacognitive awareness of olfactory ability and age in people reporting chemosensory disturbances. Am J Psychol 116: 99-110.

12. Keller A (2011) Attention and olfactory consciousness. Frontiers in Psychology 2: 380.

13. Landis BN, Hummel T, Hugentobler M, Giger R, Lacroix JS (2003) Ratings of overall olfactory function. Chemical Senses 28: 691-694.

14. Doty RL, Reyes PF, Gregor T (1987) Presence of both odor identification and detection deficits in Alzheimer's disease. Brain Research Bulletin 18: 597-600.

15. Wehling E, Lundervold AJ, Espeset T, Reinvang I, Bramerson A, et al. (2015) Even cognitively well-functioning adults are unaware of their olfactory dysfunction: Implications for ENT clinicians and researchers. Rhinology 53: 89-94. 
16. Murphy C, Schubert CR, Cruickshanks KJ, Klein BEK, Klein R, et al. (2002) Prevalence of olfactory impairment in older adults. JAMA 288: 2307-2312.

17. Nordin S, Monsch AU, Murphy C (1995) Unawareness of smell loss in normal aging and Alzheimer's disease: discrepancy between self-reported and diagnosed smell sensitivity. J Gerontol B Psychol Sci Soc Sci 50: 187-192.

18. Rawal S, Hoffman HJ, Chapo AK, Duffy VB (2014) Sensitivity and Specificity of Self-Reported Olfactory Function in a Home-Based Study of Independent-Living, Healthy Older Women. Chemosens Percept 7: 108-116.

19. Rawal S, Hoffman HJ, Honda M, Huedo-Medin TB, Duffy VB (2015) The Taste and Smell Protocol in the 2011-2014 US National Health and Nutrition Examination Survey (NHANES): Test-Retest Reliability and Validity Testing. Chemosens Percept 8: 138-148.

20. Doty RL (2017) Olfactory dysfunction in neurodegenerative diseases: is there a common pathological substrate? Lancet Neurol 16: 478-488.

21. Barresi M, Ciurleo R, Giacoppo S, Foti Cuzzola V, Celi D, et al. (2012) Evaluation of olfactory dysfunction in neurodegenerative diseases. Journal of the Neurological Sciences 323: 16-24.

22. Devanand DP, Michaels-Marston KS, Liu X, Pelton GH, Padilla M, et al. (2000) Olfactory deficits in patients with mild cognitive impairment predict Alzheimer's disease at follow-up. The American Journal of Psychiatry 157: 13991405.

23. Growdon ME, Schultz AP, Dagley AS, Amariglio RE, Hedden T, et al. (2015) Odor identification and Alzheimer disease biomarkers in clinically normal elderly. Neurology 84: 2153-2160.

24. Picillo M, Pellecchia MT, Erro R, Amboni M, Vitale C, et al. (2014) The use of University of Pennsylvania Smell Identification Test in the diagnosis of Parkinson's disease in Italy. Neurol Sci 35: 379-383.

25. Liepelt-Scarfone I, Gauss K, Maetzler W, Muller K, Bormann $\mathrm{C}$, et al. Evaluation of progression markers in the premotor phase of Parkinson's disease: the progression markers in the premotor phase study. Neuroepidemiology 41: 174-182.

26. Cook A, Pfeiffer LM, Thiele S, Coenen VA, Döbrössy MD (2017) Olfactory discrimination and memory deficits in the Flinders Sensitive Line rodent model of depression. Behavioural processes 143: 25-29.

27. Temmel AFP, Quint C, Schickinger-Fischer B, Klimek L, Stoller E, et al. (2002) Characteristics of olfactory disorders in relation to major causes of olfactory loss. Arch Otolaryngol Head Neck Surg 128: 635-641.

28. Zucco GM, Bollini F (2011) Odour recognition memory and odour identification in patients with mild and severe major depressive disorders. Psychiatry Res 190: 217-220.

29. Boyle PA, Wilson RS, Aggarwal NT, Tang Y, Bennett DA (2006) Mild cognitive impairment: risk of Alzheimer disease and rate of cognitive decline. Neurology 67: 441-445.

30. Gaudreau P, Morais JA, Shatenstein B, Gray-Donald K, Khalil A, et al. (2007) Nutrition as a determinant of successful aging: description of the Quebec longitudinal study Nuage and results from cross-sectional pilot studies. Rejuvenation Res 10: 377-386.
31. Krajnik J, Kollndorfer K, Notter LA, Mueller CA, Schopf V (2015) The impact of olfactory dysfunction on interoceptive awareness. Psychophysiology 52: 263-268.

32. Djordjevic J, Jones-Gotman M, De Sousa K, Chertkow H (2008) Olfaction in patients with mild cognitive impairment and Alzheimer's disease. Neurobiol Aging 29: 693-706.

33. Canada S (2012) Living arrangements of seniors. Ottawa, Canada.

34. Duff K, McCaffrey RJ, Solomon GS (2002) The Pocket Smell Test: successfully discriminating probable Alzheimer's dementia from vascular dementia and major depression. The Journal of Neuropsychiatry and Clinical Neurosciences 14: 197-201.

35. Kjelvik G, Saltvedt I, White LR, Stenumgård P, Sletvold $O$, et al. (2014) The brain structural and cognitive basis of odor identification deficits in mild cognitive impairment and Alzheimer's disease. BMC Neurol 14: 168.

36. Vasavada MM, Wang J, Eslinger PJ, Gill DJ, Sun X, et al. (2015) Olfactory cortex degeneration in Alzheimer's disease and mild cognitive impairment. J Alzheimers Dis 45: 947-958.

37. Cain WS, Stevens JC, Nickou CM, Giles A, Johnston I, et al. (1995) Life-span development of odor identification, learning, and olfactory sensitivity. Perception 24: 14571472.

38. Hummel T, Rissom K, Reden J, Hähner A, Weidenbecher $\mathrm{M}$, et al. (2009) Effects of olfactory training in patients with olfactory loss. The Laryngoscope 119: 496-499.

39. Pekala K, Chandra RK, Turner JH (2016) Efficacy of olfactory training in patients with olfactory loss: a systematic review and meta-analysis. Int Forum Allergy Rhinol 6: 299307.

40. Wysocki CJ, Dorries KM, Beauchamp GK (1989) Ability to perceive androstenone can be acquired by ostensibly anosmic people. Proc Natl Acad Sci USA 86: 7976-7978.

41. Barnard ND, Bush Al, Ceccarelli A, Cooper J, de Jager CA, et al. (2014) Dietary and lifestyle guidelines for the prevention of Alzheimer's disease. Neurobiology of Aging 35: S74-S78.

42. Jimbo D, Kimura $Y$, Taniguchi $M$, Inoue $M$, Urakami $K$ (2009) Effect of aromatherapy on patients with Alzheimer's disease. Psychogeriatrics 9: 173-179.

43. Larson EB, Wang L, Bowen JD, McCormick WC, Teri L, et al. (2006) Exercise is associated with reduced risk for incident dementia among persons 65 years of age and older. Annals of Internal Medicine 144: 73-81.

44. Radak Z, Hart N, Sarga L, Koltai E, Atalay M, et al. (2010) Exercise plays a preventive role against Alzheimer's disease. J Alzheimers Dis 20: 777-783.

45. Solfrizzi V, Panza F, Frisardi V, Seripa D, Logroscino G, et al. (2011) Diet and Alzheimer's disease risk factors or prevention: the current evidence. Expert Rev Neurother 11: 677-708.

46. Jackman AH, Doty RL (2005) Utility of a three-item smell identification test in detecting olfactory dysfunction. The Laryngoscope 115: 2209-2212. 
Supplemental Table 1: Quantitative smell tests currently in use.

\begin{tabular}{|c|c|c|}
\hline Test name & $\begin{array}{l}\text { Number of items/ } \\
\text { different odors }\end{array}$ & Internet source \\
\hline Smell Identification Test (UPSIT) [1,2] & 40 different odors & $\begin{array}{l}\text { https://sensonics.com/smell-identification-test-international- } \\
\text { versions-available.html }\end{array}$ \\
\hline Snap \& Sniff Olfactory Test System [3] & $\begin{array}{l}20 \text { items test } \\
\text { (Threshold) }\end{array}$ & https://sensonics.com/snapandsniffolfactorytests.html \\
\hline Sniffin' Sticks Identification Test 16 [4-6] & 16 different odors & $\begin{array}{l}\text { https://smelltest.eu/en/product/burghart-sniffin-sticks- } \\
\text { identification-test-16-blue/ }\end{array}$ \\
\hline Screening 12 Test $[7,8]$ & 12 different odors & $\begin{array}{l}\text { http://smelltest.eu/en/product/buy-burghart-sniffin-sticks- } \\
\text { smelltest-pens/ }\end{array}$ \\
\hline Brief Smell Identification Test $[9,10]$ & 12 different odors & https://sensonics.com/brief-smell-identification-test.html \\
\hline Odor Discrimination/Memory Test $[11,12]$ & $\begin{array}{l}12 \text { items test using } \\
4 \text { different odors }\end{array}$ & https://sensonics.com/smell-products/odor-memory-test.html \\
\hline The Pediatric Smell Wheel [13] & 11 different odors & $\begin{array}{l}\text { https://sensonics.com/smell-products/the-pediatric-smell- } \\
\text { wheel.html }\end{array}$ \\
\hline NIH Toolbox Odor Identification Test [14] & 9 different odors & $\begin{array}{l}\text { http://www.healthmeasures.net/explore-measurement- } \\
\text { systems/nih-toolbox/intro-to-nih-toolbox/sensation }\end{array}$ \\
\hline Smell Diskettes [15] & 8 different odors & http://www.smelldiskettes.com/en/gebrauchsanweisung.php \\
\hline 4-Item NHANES Pocket Smell Test [16] & 4 different odors & $\begin{array}{l}\text { https://sensonics.com/smell-products/pocket-smell-test-50. } \\
\text { html }\end{array}$ \\
\hline Quick Smell Identification Test [17] & 3 different odors & $\begin{array}{l}\text { https://sensonics.com/smell-products/quick-smell- } \\
\text { identification-test.html }\end{array}$ \\
\hline Pocket Smell Test [18] & 3 different odors & https://sensonics.com/smell-products/pocket-smell-test.html \\
\hline
\end{tabular}

\section{Supplemental Table References}

1. Doty RL, Shaman P, Applebaum SL, Giberson R, Siksorski L, et al. (1984) Smell identification ability: changes with age. Science 226: 1441-1443.

2. Doty RL, Shaman P, Kimmelman CP, Dann MS (1984) University of Pennsylvania Smell Identification Test: a rapid quantitative olfactory function test for the clinic. Laryngoscope 94: 176-178.

3. Jiang RS, Liang KL (2018) A Pilot Study of the Snap \& Sniff Threshold Test. Ann Otol Rhinol Laryngol 127: 312-316.

4. Lawton M, Hu MT, Baig F, Ruffmann C, Barron E, et al. (2016) Equating scores of the University of Pennsylvania Smell Identification Test and Sniffin' Sticks test in patients with Parkinson's disease. Parkinsonism Relat Disord 33: 96-101.

5. Kang W, Dong F, Li D, Quinn TJ, Chen S, et al. (2016) The predictive value of SS-16 in clinically diagnosed Parkinson's disease patients: comparison with $(99 \mathrm{~m}) \mathrm{Tc}$-TRODAT-1 SPECT scans. Transl Neurodegener 5: 15.

6. Bastos LO, Guerreiro MM, Lees AJ, Warner TT, SilveiraMoriyama L (2015) Effects of age and cognition on a cross-cultural paediatric adaptation of the Sniffin' Sticks Identification Test. PLoS One 10: e0131641.

7. Eibenstein A, Fioretti AB, Lena C, Rosati N, Ottaviano I, et al. (2005) Olfactory screening test: experience in 102 Italian subjects. Acta Otorhinolaryngol Ital 25: 18-22.

8. Ottaviano G, Savietto E, Scarpa B, Bertocco A, Maculan P, et al. (2018) Influence of number of drugs on olfaction in the elderly. Rhinology 56: 351-357.

9. Double KL, Rowe DB, Hayes M, Chan DKY, Blackie J, et al. (2003) Identifying the pattern of olfactory deficits in Parkinson disease using the brief smell identification test. Archives of Neurology 60: 545-549.

10. Menon C, Westervelt HJ, Jahn DR, Dressel JA, O'Bryant

SE (2013) Normative performance on the Brief Smell Identification Test (BSIT) in a multi-ethnic bilingual cohort: a Project FRONTIER study. Clin Neuropsychol 27: 946-961.

11. Choudhury ES, Moberg P, Doty RL (2003) Influences of age and sex on a microencapsulated odor memory test. Chem Senses 28: 799-805.

12. Doty RL, Tourbier I, Ng V, Neff J, Armstrong D, et al. (2015) Influences of hormone replacement therapy on olfactory and cognitive function in postmenopausal women. Neurobiol Aging 36: 2053-2059.

13. Cameron EL, Doty RL (2013) Odor identification testing in children and young adults using the smell wheel. Int $J$ Pediatr Otorhinolaryngol 77: 346-350.

14. Dalton P, Doty RL, Murphy C, Frank R, Hoffman HJ, et al. (2013) Olfactory assessment using the NIH Toolbox. Neurology 80: S32-S36.

15. Briner HR, Simmen D (1999) Smell diskettes as screening test of olfaction. Rhinology 37: 145-148.

16. Liu G, Zong G, Doty RL, Sun Q (2016) Prevalence and risk factors of taste and smell impairment in a nationwide representative sample of the US population: a crosssectional study. BMJ Open 6: e013246.

17. Jackman AH, Doty RL (2005) Utility of a three-item smell identification test in detecting olfactory dysfunction. Laryngoscope 115: 2209-2212.

18. Duff K, McCaffrey RJ, Solomon GS (2002) The Pocket Smell Test: successfully discriminating probable Alzheimer's dementia from vascular dementia and major depression. The J Neuropsychiatry Clin Neurosci 14: 197-201.
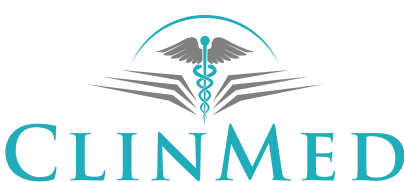

INTERNATIONAL LIBRARY 